\title{
THE WEIGHT OF EXPECTANCY-VALUE AND ACHIEVEMENT GOALS ON SCIENTIFIC CAREER INTEREST AND MATH ACHIEVEMENT
}

\author{
Laura Francesca Scalas* and Daniela Fadda* \\ Dipartimento di Pedagogia, Psicologia, Filosofia - Università degli Studi di Cagliari, Italy
}

\begin{abstract}
The study explored a taxonomy of alternative latent models to understand the weight of expectancy-value and approach-related goal orientations in predicting students' achievement behaviors (scientific career interest and math achievement). A full model where all the factors contribute to explaining the total variance of outcomes and two models in which the contribution of expectancy-value and achievement goals factors was evaluated separately within a structural equation modeling framework. Results, among a sample of 812 Italian high school students (486 males and 326 females, Mage $=18.3$ ), showed that expectancy-value variables explain a substantial portion of math achievement and career interest variance after controlling for the achievement goals. Moreover, when all path coefficients were allowed (full model), global value and its dimensions of opportunity and emotional cost influenced positively student's career aspirations, expectancy resulted the main predictor of math competence, and mastery and performance goals did not show significant effects on the outcomes.
\end{abstract}

\section{KEYWORDS}

Motivation, Expectancy-Value, Achievement Goals, Scientific Career Interest, Math Achievement

\section{INTRODUCTION}

To understand motivation in several educational domains including math, researchers suggested the importance of two broad constructs: expectancy-value and achievement goal orientations (Eccles and Wigfield, 2002; Pintrich, 2003; Simpkins, Davis-Kean and Eccles, 2006; Wigfield and Cambria, 2010).

Based on expectancy-value theory (EVT; Eccles, 2009; Eccles et al., 1983), expectancy of success in a given task in combination with the value of the task (intrinsic value, attainment value, utility value, and cost) predict academic achievement, effort, engagement and career choices (Eccles, 2009; Guo et al., 2015; Watt et al., 2012). In particular, expectancy typically is the strongest predictor of achievement, whereas value influences career aspirations (Eccles and Wigfield, 2002; Marsh et al., 2013; Simpkins et al., 2006).

Concerning achievement goals, Elliot and colleagues (e.g., Elliot, 1999; Elliot and McGregor, 2001) distinguish between mastery (focused on development of competence) and performance (focused on demonstration of competence) goals. Empirical studies showed that mastery approach goals positively predict students' interest and course enjoyment, whereas performance goals have different effects on learning processes, depending on approach and avoidance orientations, which respectively focus on reaching positive outcomes and on eluding negative outcomes (e.g., Elliot, 1999; Elliot and McGregor, 2001; Elliot and Murayama, 2008; Hulleman et al., 2008).

Although goals and expectancy-value variables are empirically distinct and are independent predictors of achievement-related behaviors (DeBacker and Nelson, 1999; Miller, DeBacker and Greene, 1999; Wigfield, Anderman and Eccles, 2000), several studies in academic domain have investigated associations and causal direction of these factors (Conley, 2012; DeBacker and Nelson, 1999; Miller et al., 1999; Pintrich et al., 1993). Indeed, in line with Eccles's theory (Eccles et al., 1983; Wigfield and Eccles, 1992), longitudinal studies supported the predictive effect of achievement goals on value, considered a motivational construct

*The two authors contributed equally to the present study and should be considered both first author. 
subordinated in respect to goals (Harackiewicz et al., 2002, 2008; Hulleman et al., 2008; Pintrich, Ryan and Patrick, 1998; Wolters, Yu and Pintrich, 1996); studies based on a different conception posit, instead, a possible causal influence of expectancy and value on goals (Greene et al., 1999, 2004; Liem, Lau and Nie, 2008; Plante, O'Keefe and Théorêt, 2013), considered as specific orientations towards a domain (Elliot, 2006; Meece, Anderman and Anderman, 2006). As suggested by Wigfield and Cambria's (2010) review about extant research on students' motivation, the exploration of these constructs together is an important way to understand the nature of achievement motivation.

Aim of the present study is to understand the weight of expectancy-value and approach-related goals on individuals' achievement behaviors in mathematical domain (scientific career interest and math achievement). Indeed, although both motivational theories appear to be involved in the determination of academic outcomes, their relationship is still unclear. To overcome this limitation, we compare a taxonomy of models, based on Marsh and Scalas (2018), to understand the weight of each motivational attribute in predicting the outcomes (see Figure 1). In particular, we evaluate the total variance explained by a full model in which the path coefficients of both motivational predictors are freely estimated, and the unique variance explained by only a set of predictor variables after controlling for the other predictors: the expectancy-value prediction model (e.g., Eccles, 2009; Guo et al., 2015) and the achievement goals prediction model (e.g., Harackiewicz et al., 2002; Hulleman et al., 2008). Although an examination of the explained variance is not common practice in structural equation modeling, this approach has been suggested as a relevant criterion in the comparison-model process (e.g., Marsh and Scalas, 2018; Scalas et al., 2014).

Measurement model

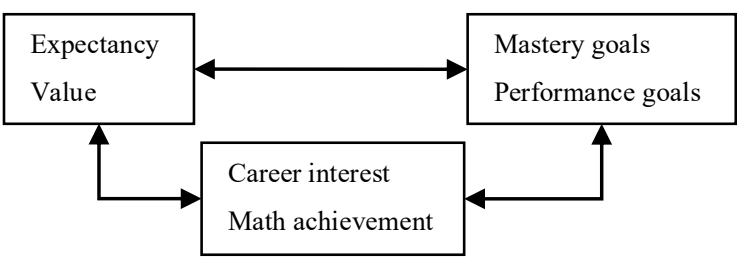

Expectancy-value prediction model

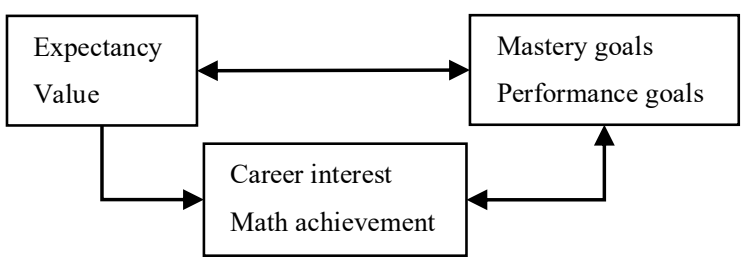

Full model

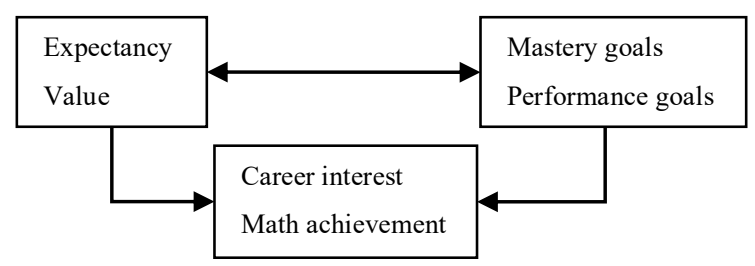

Achievement goals prediction model

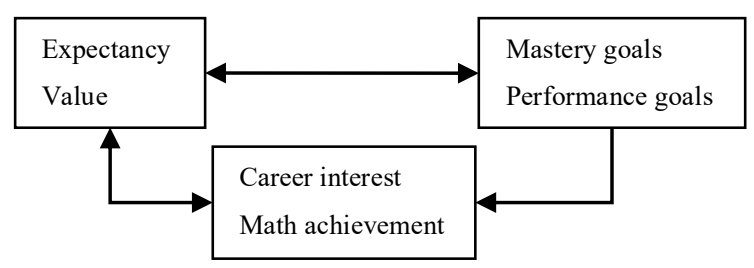

Figure 1. Simplified conceptual representations of estimated models. Two-headed arrows represent latent correlations and one-headed arrows represent regression paths with the outcome variables receiving the arrowhead

\section{METHOD}

\subsection{Participants}

This study relies on a convenience sample of 812 Italian high school students $\left(12^{\text {th }}\right.$ and $13^{\text {th }}$ Grades; 486 males and 326 females, Mage $=18.3, S D=.89$ ). Each student received a parental consent form, with information about the study. On the testing date, active consent was sought from the students. The participants anonymously completed the questionnaires in 20-minute group sessions, during school hours. Confidentiality was guaranteed. 


\subsection{Measures}

All participants completed an Italian version of the value scale (Fadda et al., 2018). This version includes 37 items (e.g., Math is fun to me) measuring 9 specific factors (intrinsic, $\omega=.97$; importance of achievement, $\omega=.86$; personal importance, $\omega=.62$; utility for school/job, $\omega=.90$; utility for life, $\omega=.97$; social utility, $\omega$ $=.96$; effort required, $\omega=.93$; opportunity cost, $\omega=.97$; emotional cost, $\omega=.95$ ) and one global value factor $(\omega=.99)$. Items were rated on a 6 -point Likert scale $(1=$ strongly disagree to $6=$ completely agree $)$.

Participants also completed the mastery (e.g., I want to learn as much as possible from this class; $\omega=.99$ ) and performance approach (e.g., My goal in this class is to get a better grade than most of the other students; $\omega=.99)$ scales of the Achievement goals questionnaire (Elliott and McGregor, 2001) applied to mathematics (6 items; $1=$ false to $6=$ true).

Expectancy was measured by five items (e.g., I find many mathematical problems interesting and challenging; Likert scale from $1=$ false to $6=$ true; $\omega=.99$ ) of the mathematics scale from the Self-Description Questionnaire (SDQ-II; Marsh, 1992). As regards the outcome variables, career aspirations were measured by three items (e.g., I expect to work in a job uses science; $\omega=.99$ ), with a 6-point response scale (from $1=$ strongly disagree to $6=$ completely agree), taken from the Program for International Student Assessment (OECD, 2006, 2007). A score of mathematics competence (from 0 to 5) was computed by the sum of the responses to a logical-mathematical test composed of five items, with five-answer options scored as dichotomous (correct/incorrect).

\subsection{Analyses}

Within a structural equation modeling framework (SEM; Bollen, 1989), we contrasted alternative latent models using Mplus 7.3 (Muthén and Muthén, 2014) with robust maximum likelihood (MLR) estimator and Full Information Maximum Likelihood (FIML; Enders, 2010) to handle missing data present at the item level $(0.1 \%$ to $1.7 \%, M=0.7 \%)$. A SEM model allows the researcher to examine at the same time several links (correlations or regression paths) among various variables by taking into account the measurement error that in regular analyses based on scale scores could bias the results. In standardized solutions, as the ones reported here, all latent variables are set with a variance equal to 1 and this allows to interpret correlations and betas as in regular analyses based on scale scores. Therefore, for correlations and betas, values close to zero indicate absence of association, whereas values close to one indicate very strong relations, and values around .5 indicate moderate relations among the variables. The ability of the model to fit the data is measured with various indices (e.g., CFI, TLI) and in predictive models it is possible to evaluate how much variance of the outcomes can be explained by the predictors (R2). Comparison between alternative models provides, therefore, an effective way to study relationships between the variables taking into account the measurement error.

Following Marsh and Scalas taxonomy (2008), first, we tested a measurement model in which all factors are merely correlated (model 0 ). Second, to ensure the same degree of complexity (equivalent number of estimated parameters, degrees of freedom and fit indices), the predictive models were built as follows: 1) the full prediction model includes effects (path coefficients) of expectancy, value, and goals variables on the outcomes; 2) the expectancy-value prediction model includes effects of expectancy-value on the outcomes and correlations between goals and outcomes; 3) the achievement goals prediction model includes effects of goals on the outcomes and correlations between expectancy-value and outcomes (see Table 1). Moreover, to examine the change in fit associated to the release of specific betas, we tested complementary solutions to models 2 and 3. In particular, in relation to model 2, we changed covariances to paths and we fixed the goals paths to be zero (model2a); in relation to model 3, we changed covariances to paths and fixed the expectancy-value paths to be zero (model3a).

We examined the total variance explained by the predictors $\left(\mathrm{R}^{2}\right)$ and the following goodness-of-fit indexes: the chi-square $\left(\chi^{2}\right)$ test of exact fit, the comparative fit index (CFI), the Tucker-Lewis Index (TLI), and the root mean square error of approximation (RMSEA). CFI and TLI vary from 0 to 1 , with values close to 1 indicating a better fit. For RMSEA, values lower than .06 indicate a potentially better fit (Hu and Bentler, 1999), although no golden rules have been established (Marsh, Hau and Wen, 2004). To test differences among nested models $(1,2 \mathrm{a}, 3 \mathrm{a})$, we computed the Satorra-Bentler scaled chi-square difference test $\left(\Delta \chi^{2}\right)$ based on scaling correction factors obtained with the MLR estimator (Satorra and Bentler, 2010). 
Table 1. Taxonomy of models used. Each path coefficient is freely estimated (free) or specified as a covariance rather than a regression path $(0)$

\begin{tabular}{lllll}
\hline Model & Expectancy & Value & Mastery goals & Performance goals \\
\hline Measurement & 0 & 0 & 0 & 0 \\
Full & free & free & free & free \\
Expectancy-value & free & free & 0 & 0 \\
Achievement goals & 0 & 0 & free & free \\
\hline
\end{tabular}

\section{RESULTS}

\subsection{Structure of Value and Goals Scales}

In line with the Italian validation (Fadda et al., 2018) the value beliefs scale in math was measured including a bifactor component to the exploratory structural equation modeling (ESEM; Morin, Arens and Marsh, 2016). This solution allows items to reflect both a global overarching construct (G-factor) and its specific components. The bifactor-ESEM solution was estimated using a bifactor orthogonal target rotation (Reise, 2012) in which all cross-loadings were "targeted" to be close to zero, whereas all the main loadings were freely estimated as in the CFA model. The model showed adequate fit indices $\left(\chi^{2}=523.265 ; d f=340\right.$; $\mathrm{CFI}=.988 ; \mathrm{TLI}=.977$; RMSEA $=.026$ ).

Since the Achievement goals questionnaire (Elliott and McGregor, 2001) applied to mathematics was not validated in the Italian context, we tested the measurement model with CFA procedures. Results showed adequate fit indices $\left(\chi^{2}=52.972 ; d f=8 ; \mathrm{CFI}=.972\right.$; TLI $\left.=.948 ; \mathrm{RMSEA}=.083\right)$ and factor loading ranged from .56 to .86 for the mastery approach scale and from .80 to .89 for the performance approach scale. Intercorrelation was $r=.50$. Finally, a latent model of the logical-mathematical test showed adequate fit indices $\left(\chi^{2}=10.114 ; d f=5 ; \mathrm{CFI}=.987\right.$; TLI $=.974 ;$ RMSEA $=.036$ ), factor loadings (from .42 to .58$)$ and reliability $(\omega=.97)$.

\subsection{Models Comparison}

In the measurement model all the factors (expectancy-value, achievement goals, scientific career interest, mathematics achievement) are allowed to be correlated without positing causal ordering. Results showed adequate fit indices $(\mathrm{CFI}=972$; $\mathrm{TLI}=.959$; RMSEA $=.030)$. Correlations among the variables are showed in Table 2.

Table 2. Measurement model correlations. ** $\mathrm{p}<.01 ; * \mathrm{p}<.05$

\begin{tabular}{|c|c|c|c|c|c|}
\hline & $\begin{array}{l}\text { Career } \\
\text { interest }\end{array}$ & $\begin{array}{c}\text { Math } \\
\text { achievement }\end{array}$ & $\begin{array}{c}\text { Mastery } \\
\text { goals }\end{array}$ & $\begin{array}{l}\text { Performance } \\
\text { goals }\end{array}$ & Expectancy \\
\hline Career interest & 1 & & & & \\
\hline Math achievement & $.354 * *$ & 1 & & & \\
\hline Mastery goals & $.413 * *$ & $.183 * *$ & 1 & & \\
\hline Performance goals & $.262 * *$ & $.083^{*}$ & $.501 * *$ & 1 & \\
\hline Expectancy & $.429 * *$ & $.401 * *$ & $.461 * *$ & $.446 * *$ & 1 \\
\hline Global value & $.335 * *$ & $.083^{*}$ & $.574 * *$ & $.383 * *$ & $.463 * *$ \\
\hline intrinsic & $.206 * *$ & $.255^{* *}$ & & $.148 * *$ & $.597 * *$ \\
\hline $\begin{array}{l}\text { importance of achievement } \\
\text { personal importance }\end{array}$ & & & $\begin{array}{r}.118^{*} \\
.276^{* *}\end{array}$ & $.161 * *$ & $.124 * *$ \\
\hline utility for school/job & & & $-.132 *$ & $-.114 *$ & $-.134 * *$ \\
\hline utility for life & & $-.101 *$ & $-.079 *$ & $-.101 *$ & \\
\hline social utility & & & & $.387 * *$ & \\
\hline effort required & & & $.168 * *$ & & $-.126^{* *}$ \\
\hline opportunity cost & $.304 * *$ & $.239 * *$ & $.304 * *$ & $.109 * *$ & $.182 * *$ \\
\hline emotional cost & $.241 * *$ & & $.298 * *$ & $.103^{*}$ & $.135 * *$ \\
\hline
\end{tabular}


Models 1, 2 and 3 present the same number of estimated parameters, degrees of freedom, and fit indices as the measurement model (see Table 3). However, some relations between the predictors and the outcomes are expressed as betas in some models and as correlations in other models. Therefore, it is possible to distinguish between total and unique variance explained by different sets of predictors. The expectancy-value prediction model showed that a substantial amount of variance can be explained by these factors, whereas the variance explained by the achievement goals prediction model is smaller but still statistically significant (see Table 3).

The chi-square difference test based on the difference between the full model and the other nested models (2a and 3a) showed a statistically significant difference for the achievement goals model (model 3a). In this model the effects of expectancy-values variables on outcomes were excluded. On the contrary, no significant chi-square difference was found comparing the full model with for model $2 \mathrm{a}$, where the effects of goals were set to zero (see Table 3).

Table 3. Models fit indices and explained variance of outcomes. Scf is the scaling correction factor for MLR; $\mathrm{R}^{2}$ is the variance in the outcomes explained by predictor variables; the chi-square difference test $\left(\Delta \chi^{2}\right)$ is based on the difference between the full model and each nested model.** $\mathrm{p}<.01 ; * \mathrm{p}<.05$

\begin{tabular}{lccccccccc}
\hline Model & $\chi^{2}$ & df & scf & CFI & TLI & RMSEA & $\begin{array}{c}\mathrm{R}^{2} \\
\text { Math achievement }\end{array}$ & $\begin{array}{c}\mathrm{R}^{2} \\
\text { Career interest }\end{array}$ & $\Delta \chi^{2}(\mathrm{df})$ \\
\hline 0 & 1613.238 & 926 & 1.186 & .972 & .959 & .030 & N/A & N/A & $.328^{* *}$ \\
1 & 1613.238 & 926 & 1.186 & .972 & .959 & .030 & $.228^{* *}$ & $.326^{* *}$ & $.175^{*}$ \\
2 & 1613.238 & 926 & 1.186 & .972 & .959 & .030 & $.222^{* *}$ & & $5.692(4)$ \\
3 & 1613.238 & 926 & 1.186 & .972 & .959 & .030 & $.034^{* *}$ & & $155.341(12)^{* *}$ \\
\hline $\mathrm{a}$ & 1618.931 & 930 & 1.186 & .972 & .959 & .030 & & & \\
$3 \mathrm{a}$ & 1789.257 & 948 & 1.191 & .965 & .951 & .033 & & & \\
\hline
\end{tabular}

Concerning effects of predictors on the outcomes, results showed that in the full model, goals did not affect scientific career interest and math achievement of students. Scientific career interest was positively predicted by global value and its dimensions related to cost (opportunity and emotional cost). Math achievement was positively predicted by expectancy and opportunity cost; negatively predicted by utility for life (see Table 4).

The expectancy-value prediction model in which the coefficients of mastery and performance goals were specified as covariances rather than paths, showed pattern of results similar to the full model. Scientific career interest was positively predicted by global value, opportunity and emotional cost. Math achievement was positively predicted by expectancy and opportunity cost; negatively predicted by global value and utility for life (see Table 4). In the achievement goals prediction model, where only goals influences were allowed, scientific career interest and math achievement were predicted by mastery goals (see Table 4).

Table 4. Effects of predictors on the outcomes in the model tested. Model 1: full model; model 2: expectancy-value prediction model; model 3: achievement goals prediction model. Only significant coefficients are reported in this table In bold are path coefficients; non-bold values represent covariances. ${ }^{* *} \mathrm{p}<.01 ;{ }^{*} \mathrm{p}<.05$

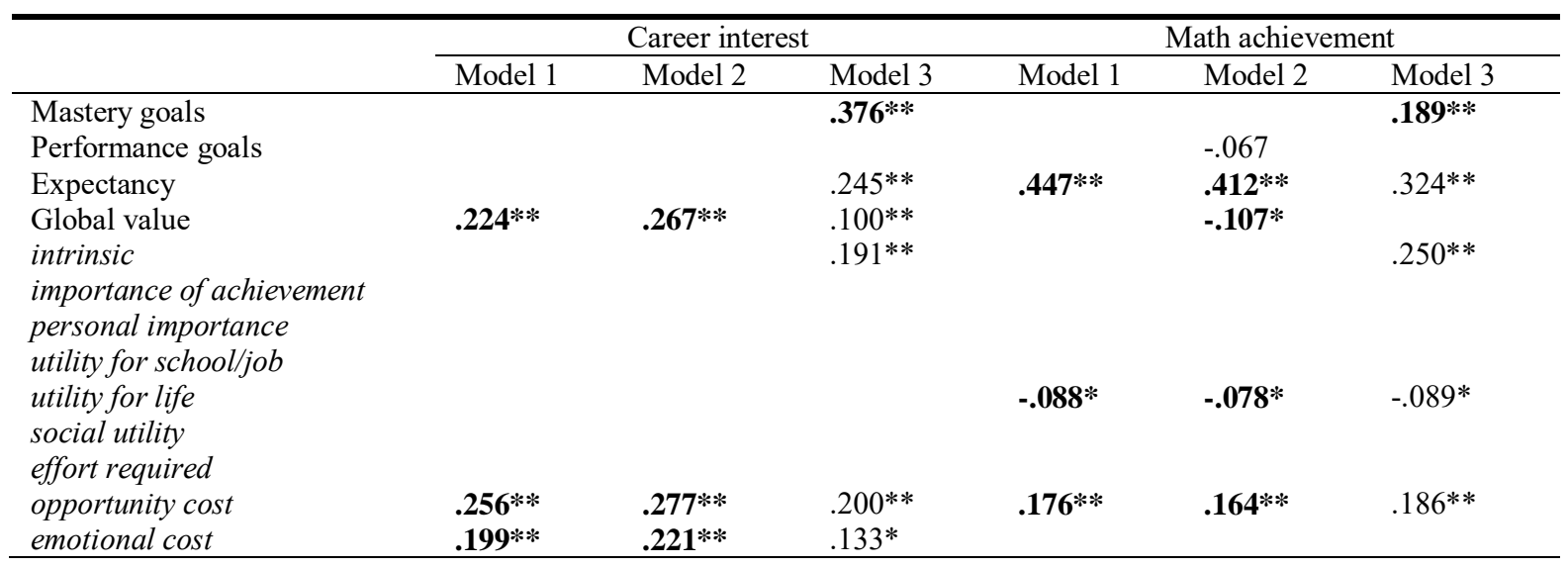




\section{DISCUSSION}

Achievement goals theory (e.g., Elliot, 1999) and expectancy-value models (e.g., Eccles et al., 1983) are both important to understand motivation and achievement, but rarely they have been integrated in the same study (e.g., Conley, 2012; Hulleman et al., 2008; Plante et al., 2013), therefore their relationship remains unclear.

Our main aim was to explore alternative models to understand the weight of expectancy-value and goals in predicting career interest and math achievement. Specifically, we contrasted a taxonomy of models to disentangle the role of these factors: 1) a full model where all the factors contribute to the explanation of the outcomes' variance, 2) one model in which we evaluated the specific contribution of expectancy-value, and 3 ) another model in which we examined the specific contribution of achievement goals factors. Based on Marsh and Scalas (2018) study, we have evaluated the change in the explained variance in each one of the tested models.

Results showed that much of the variance in the outcomes that can be explained by the full model can also be explained by the expectancy-value model alone. This result is inconsistent with Conley (2012) study in a middle school students' sample that supported the importance of considering both goals and value to improve math achievement predictions. In the achievement goals prediction model the variance explained by predictors is considerably smaller, especially with regards to math achievement, and the chi-square difference test showed that this model fits significantly worse than the full model if expectancy-value variables are excluded as predictors. Moreover, in the full model, we did not find any influence of mastery or performance goals on the outcomes. Therefore, results suggested that to understand math competence and scientific career interest outcomes, approach-related achievement goals applied to mathematics do not add much to what can already be explained in terms of expectancy and value.

A possible interpretation comes from the expectancy-value theory (Eccles, 2005; Eccles et al., 1983; Wigfield and Eccles, 1992). According to this conception, task value is a motivational construct subordinated in respect to achievement goals, which should be considered general directions of behaviors (e.g., preference for challenging or competitive tasks; Maehr and Zusho, 2009). In academic domain, longitudinal studies supported the predictive effect of mastery goals on value and the mediation role of intrinsic and utility value on school performance (Harackiewicz et al., 2002, 2008; Hulleman et al., 2008; Pintrich et al., 1998; Wolters et al., 1996). Therefore, goals could act on achievement-related outcomes not directly but via more specific expectancy and value variables.

Consistent with previous literature, where expectancy showed a strong influence on achievement and value influenced choice, effort, and persistence in achievement-related activities (e.g., Eccles and Wigfield, 2002; Marsh et al., 2013), in the present study, a high global value placed on math positively influenced student's career aspirations in science, and expectancy resulted the main predictor of math competence.

Moreover, it should be noted that to perceive high costs in term of time lost for other activities (i.e., opportunity cost) brings students to greater mathematics achievement and scientific career plans. Results showed also, in both models, a negative influence of utility for life on mathematics achievement; this dimension composed of different life domains, from short-term (such as daily routines and leisure time activities) to long term utility (such as unspecified future life activities) has an instrumental nature and it captures the extrinsic motivation for engagement and achievement in a specific task (Ryan and Deci, 2009).

\section{CONCLUSION}

Our findings based on the comparison of alternative models showed that expectancy-value variables explain a substantial portions of math achievement and career interest variance in respect to achievement goals. Moreover, although caution is required to infer causality from self-reports measures, value and its dimensions resulted the only variables influencing student's career aspiration, and consistent with previous literature expectancy resulted the principal predictor of math competence in the high school context. It should be noted, that we considered students attending the last class of high school, thus it is possible that younger students might have fewer concrete ideas about their future and thus general goals could be more predictive of specific outcomes. Finally, our items were limited to the domain of mathematics and future research might expand model comparison to other academic domains. 
Overall, our results suggest that although the study of approach-related achievement goals and their promotion in long-term researches are important for the development of the youth's motivation system, in applied studies, for researchers interested in direct promotion of the high school students' mathematics achievement or future intentions regarding scientific career, it would be more useful to focus interventions on expectancy-value variables.

\section{REFERENCES}

Bollen, K.A., 1989. Structural Equations with Latent Variables. John Wiley \& Sons, New York.

Conley, A. M. (2012). Patterns of motivation beliefs: Combining achievement goal and expectancy-value perspectives. Journal of Educational Psychology, Vol. 104, pp.32-47.

DeBacker, T.K. and Nelson, R.M. 1999. Variations on an expectancy-value model of motivation in science. Contemporary Educational Psychology, Vol. 24, pp.71-94.

Eccles, J.S., 2005. Subjective task-value and the Eccles et al. model of achievement-related choices. In A.J. Elliot \& C.S. Dweck (Eds.), Handbook of competence and motivation (pp. 105-121). Guilford, New York, NY.

Eccles, J.S., 2009. Who am I and what am I going to do with my life? Personal and collective identities as motivators of action. Educational Psychologist, Vol. 44, pp.78-89.

Eccles, J.S. et al, 1983. Expectancies, values and academic behaviors. In J.T. Spence, (Ed.), Achievement and achievement motives (pp.75-146). Freeman, San Francisco.

Eccles, J.S. and Wigfield, A., 2002. Motivational beliefs, values, and goals. Annual Review of Psychology, Vol. 53, pp.109-132.

Elliot, A.J., 1999. Approach and avoidance motivation and achievement goals. Educational Psychologist, Vol. 34, pp.149-169.

Elliot, A.J., 2006. The hierarchical model of approach-avoidance motivation. Motivation and Emotion, Vol. 30, pp. 111-116.

Elliot, A.J. and McGregor, H., 2001. A 2x2 achievement goal framework. Journal of Personality and Social Psychology, Vol. 80, pp.501-509.

Elliot, A.J. and Murayama, K., 2008. On the measurement of achievement goals: Critique, illustration, and application. Journal of Educational Psychology, Vol. 100, pp. 613-628.

Enders, C., 2010. Applied missing data analysis. Guilford Press, New York.

Fadda, D. et al, 2019. Value beliefs about math: a bifactor-ESEM representation. European Journal of Psychological Assessment.

Greene, B.A. et al, 1999. Goals, values, and beliefs as predictors of achievement and effort in high school mathematics classes. Sex Roles, Vol. 40, pp. 421-458.

Greene, B.A. et al, 2004. Predicting high school students' cognitive engagement and achievement: Contributions of classroom perceptions and motivation. Contemporary Educational Psychology, Vol. 29, pp. 462-482.

Guo, J. et al, 2015. Directionality of the associations of high school expectancy-value, aspirations, and attainment: a longitudinal study. American Educational Research Journal, Vol. 52, pp. 371-402.

Harackiewicz, J.M. et al, 2002. Revision of achievement goal theory: Necessary and illuminating. Journal of Educational Psychology, Vol. 94, pp. 638-645.

Harackiewicz, J.M. et al, 2008. The role of achievement goals in the development of interest: Reciprocal relations between achievement goals, interest, and performance. Journal of Educational Psychology, Vol. 100, pp. 105-122.

Hu, L. and Bentler, P.M., 1999. Cutoff criteria for fit indexes in covariance structure analysis: Conventional criteria versus new alternatives. Structural Equation Modeling, Vol. 6, pp. 1-55.

Hulleman, C.S. et al, 2008. Task values, achievement goals, and interest: An integrative analysis. Journal of Educational Psychology, Vol. 100, pp. 398-416.

Liem, A.D. et al, 2008. The role of self-efficacy, task value, and achievement goals in predicting learning strategies, task disengagement, peer relationship, and achievement outcome. Contemporary Educational Psychology, Vol. 33, pp. 486-512.

Maehr, M.L. and Zusho, A., 2009. Achievement goal theory: The past, present, and future. In K. R. Wentzel \& A. Wigfield (Eds.), Handbook of motivation in school (pp. 77-104). Taylor Francis, New York.

Marsh, H.W., 1992. Self-Description Questionnaire III: A theoretical and empirical basis for the measurement of multiple dimensions of adolescent self-concept: A test manual and research monograph. Macarthur, Australia. 
Marsh, H.W. and Scalas, L.F., 2018. Individually weighted-average models: testing a taxonomic sem approach across different multidimensional/global constructs because the weights "Don't make no nevermind". Structural Equation Modeling: A Multidisciplinary Journal, Vol. 25, pp. 137-159.

Marsh, H.W. et al, 2004. In search of golden rules: comment on hypothesis-testing approaches to setting cutoff values for fit indexes and dangers in overgeneralizing Hu and Bentler's (1999) findings. Structural Equation Modeling, Vol. 11, pp. 320-341.

Marsh, H.W. et al, 2013. Moderation. In T.D. Little (Ed.), The Oxford handbook of quantitative methods (pp.361-386). Oxford University Press, Oxford.

Meece, J.L. et al, 2006. Classroom goal structure, student motivation, and academic achievement. Annual Review of Psychology, Vol. 57, pp. 487-503.

Miller, R.B. et al, 1999. Perceived instrumentality and academics: The link to task valuing. Contemporary Educational Psychology, Vol. 24, p. 250-260.

Morin, A.J.S. et al, 2016. A bifactor exploratory structural equation modeling framework for the identification of distinct sources of construct-relevant psychometric multidimensionality. Structural Equation Modeling, Vol. 23, pp. 116-139.

Muthén, L.K. and Muthén, B.O., 2014. Mplus user's guide. Muthén \& Muthén, Los Angeles.

Organization-for-Economic-Co-operation-and-Development-OECD, 2006. Evolution of Student Interest in Science and Technology Studies. Paris: Author.

Organization-for-Economic-Co-operation-and-Development-OECD, 2007. PISA-2006 science competencies for tomorrow's world. Paris: Author.

Pintrich, P.R., 2003. A motivational science perspective on the role of student motivation in learning and teaching contexts. Journal of Educational Psychology, Vol., 95, pp. 667-686.

Pintrich, P.R. et al, 1998. The differential impact of task value and mastery orientation on males' and females' self-regulated learning. In L. Hoffman, A. Krapp, K.A. Renninger and J. Baumert (Eds.), Interest and learning: Proceedings of the Seeon conference on interest and gender. Institute for Science Education Press, Kiel, Germany.

Pintrich, P.R. et al, 1993. Reliability and predictive validity of the motivational strategies for learning questionnaire. Educational and Psychological Measurement, Vol., 53, pp. 801-813.

Plante, I. et al, 2013. The relation between achievement goal and expectancy-value theories in predicting achievement-related outcomes: A test of four theoretical conceptions. Motivation and Emotion, Vol., 37, pp. 65-78.

Reise, S.P., 2012. The rediscovery of bifactor measurement models. Multivariate Behavioral Research, Vol. 47, pp. 667-696.

Ryan, R.M. and Deci, E.L., 2009. Promoting self-determined school engagement: Motivation, learning, and well-being. In K.R. Wentzel \& A. Wigfield (Eds.), Handbook of motivation in school (pp. 171-196). Taylor Francis, New York.

Satorra, A. and Bentler, P.M., 2010. Psychometrika. Vol. 75, pp. 243-248.

Scalas, L.F. et al, 2014. Importance models of the physical self: improved methodology fails to support the Jamesian model and provides support for a normative importance model. European Journal of Social Psychology, Vol., 44, pp. 154-174.

Simpkins, S.D. et al, 2006. Math and science motivation: A longitudinal examination of the links between choices and beliefs. Developmental Psychology, Vol., 42, pp. 70-83.

Watt, H.M.G. et al, 2012. Gendered motivational processes affecting high school mathematics participation, educational aspirations, and career plans: A comparison of samples from Australia, Canada, and the United States. Developmental Psychology, Vol., 48, pp. 1594-1611.

Wigfield, A. et al, 2000. Relations of children's achievement values and achievement goal orientations. Paper presented at the annual meeting of the American Educational Research Association, New Orleans.

Wigfield, A. and Cambria J., 2010. Students' achievement values, goal orientations, and interest: definitions, development, and relations to achievement outcomes. Developmental Review, Vol. 30, pp. 1-35.

Wigfield, A. and Eccles J., 1992. The development of achievement task values: A theoretical analysis. Developmental Review, Vol. 12, pp. 265-310.

Wolters, C.A. et al, 1996. The relation between goal orientation and students' motivational regulation and their use of learning strategies, effort, and classroom performance. Learning and Individual Differences, Vol. 8, pp. 211-239. 